\title{
QUESTÕES EMERGENTES PARA UM (NOVO) TEMÁRIO DA GEOGRAFIA POLÍTICA DO OESTE BAIANO
}

\author{
EMERGING ISSUES FOR A (NEW) TOPICS OF THE \\ POLITICAL GEOGRAPHY OF WESTERN BAHIA
}

\author{
Paulo Roberto Baqueiro Brandão \\ Universidade Federal do Oeste da Bahia - Barreiras - BA - Brasil
}

\begin{abstract}
Resumo: Questões políticas sempre tiveram alguma centralidade na constituição da parcela mais ocidental do território baiano. Nos dias atuais, alguns processos têm ganhado importância na escala regional. Assim, três grandes questões emergem como debates necessários para a compreensão da Geografia Política contemporânea do Oeste Baiano: (a) os litígios territoriais com os estados vizinhos (Goiás e Tocantins, principalmente, mas também Piauí e Minas Gerais), (b) a pretensa criação do Estado do Rio São Francisco e, no âmbito intrarregional, de novos municípios, (c) além da imigração de populações estrangeiras. A ideia contida neste texto é, pois, traçar um breve panorama de cada um desses temas.
\end{abstract}

Palavras-chave: Geografia Política. Oeste Baiano. Secessões. Litígios de limites. Migrações internacionais.

Abstract: Political issues have always played a central role in the development of the westernmost part of the State of Bahia. Nowadays, however, they have become relevant at a regional scale. In fact, the debate of three major emerging issues has become necessary to better understand the current political geography of Western Bahia: (a) territorial disputes with neighboring states (especially Goiás and Tocantins, but also Minas Gerais and Piauí); (b) the alleged creation of the Rio São Francisco State and new towns in the region; and (c) foreign immigration. The purpose of this article is therefore to present a brief overview of these themes.

Keywords: Political Geography. Western Bahia. Secessions. Boundary disputes. International migrations.

\section{INTRODUÇÃO}

Questões políticas sempre tiveram alguma centralidade na história da parcela mais ocidental do território baiano. A fundação de um 
assentamento religioso na confluência dos rios Grande e São Francisco (a atual cidade de Barra) - considerado por alguns historiadores como base para a dominação de um território ainda bravio na virada dos séculos XVII e XVIII - e a anexação da antiga comarca provincial pernambucana ao território da Bahia no emblemático ano de 1827 são apenas alguns dos muitos exemplos de eventos de foro político que foram fundamentais na conformação da geografia dessas vastas terras interioranas (BRANDÃO, 2009; 2010).

O próprio termo "Além São Francisco", amplamente empregado como designativo do Oeste Baiano em um passado não muito distante, tem uma conotação que une Geografia e Política. Por um lado, a denominação tem um claro caráter geográfico, na medida em que revela uma relação centro-periferia, já que a lógica locacional empregada (ou seja, o que está "aqui" e o que está "além") é, por assim dizer, "sotepolitanocêntrica"1. Por outra parte, essa centralidade que se confere à cidade de Salvador só pode ser compreendida a partir de uma perspectiva político-administrativa e econômica, o que, nunca é demais mencionar, dá-se pela sua condição de capital e principal centro financeiro, de produção e consumo da Bahia.

Nos dias atuais, outros processos têm ganhado importância na escala regional. Assim, três grandes questões emergem como debates necessários para a compreensão da Geografia Política contemporânea do Oeste Baiano: (a) os litígios territoriais com os estados vizinhos (Goiás e Tocantins, principalmente, mas também Piauí e Minas Gerais), (b) a pretensa criação do Estado do (Rio) São Francisco² e, no âmbito intrarregional, de novos municípios, (c) além da imigração de populações estrangeiras. O propósito deste texto é, pois, traçar um breve panorama de cada uma das questões aventadas, inserindo-as na

\footnotetext{
1 O termo é um neologismo e não carrega maiores pretensões conceituais. Seu emprego teve apenas o intuito de dimensionar o aspecto locacional inerente ao exemplo dado.

2 Há rejeição ao uso do topônimo "Estado do São Francisco" entre os separatistas de orientação protestante, posto que aluda diretamente ao santo católico. Decorre disso a existência de uma segunda proposta, que agrega o termo "Rio", fazendo menção, assim, apenas ao curso d'água.
}

Redes (St. Cruz Sul, Online), v. 20, n 3 - Suplemento, p. 382 - 400, set./dez. 2015383 
vasta pauta de temas atinentes à atual configuração territorial do Oeste Baiano, mas sem, no entanto, pretender esgotá-los.

Antes, porém, serão dedicadas algumas linhas ao exame das tendências da Geografia Política que se desenvolvem mediante o atual processo de redimensionamento do papel do Estado e do reconhecimento de novos agentes na conformação de relações políticoterritoriais e, em seguida, uma breve caracterização geográfico-histórica do Oeste Baiano, compondo, assim, um pano de fundo para a breve análise que se pretende empreender.

\section{A ATUAL GEOGRAFIA POLÍTICA PARA ALÉM DA CENTRALIDADE DO ESTADO}

Quando surgiu como disciplina pelas mãos do geógrafo germânico Friedrich Ratzel, em 1897, e mesmo durante muitas décadas subsequentes, a Geografia Política tratava exclusivamente de compreender as formas como o Estado (se) projetava (no) o espaço. Naqueles tempos, a disciplina formulada por Ratzel diferia do termo Geopolítica, cunhado pelo sueco Rudolf Johan Kjeller, em 1899 ou 1900 (FERNANDES, 2003), apenas pelo fato deste segundo propugnar a existência de uma ciência autônoma, algo que não era possível àquela, formalmente vinculada à Geografia.

Assim, se para Ratzel, a Geografia Política (Politische Geographie) teria sua fundação a partir da constatação de um forte vínculo do Estado com o seu território (HAESBAERT, 2002), para Kjeller, a Geopolítica (Geopolitik) é a ciência que estuda o Estado como um organismo geográfico (EVANGELISTA, 2013). Em ambos os casos, é possível notar que os autores clássicos atribuem ao Estado centralidade como agente estruturador de toda a organização política de caráter espacial.

Mais que isso: fica patente, no conjunto do pensamento de Ratzel e Kjeller, que ambos acreditavam ser o Estado o detentor da exclusividade no trato da relação entre política/poder e espaço, não cabendo margem para a aceitação de outros agentes em tal empreitada.

Exceção feita a Paul Vidal de La Blache, que, segundo Haesbaert (2002, p. 81), buscou "ampliar a noção de Geografia Política" estabelecendo os vínculos entre "o homem e o meio, a sociedade e a natureza" sem a centralidade de um poder estatal, gerações inteiras de 
geógrafos foram influenciadas pelas concepções de Geografia Política e Geopolítica desenvolvidas pelos pensadores alemão e sueco, respectivamente.

Assim, ao longo de décadas, toda a produção subsequente àquela realizada pelos pioneiros nos estudos de Geografia Política e Geopolítica buscava no Estado as respostas para os processos e fenômenos atinentes às relações de caráter político-territorial. Entre os vários estudiosos que seguiram tal tendência, vale destacar os renomados geógrafos Halford John Mackinder, Karl Haushofer, Chikao Fujisawa, Jean Brunhes e Camille Vallaux, entre outros.

A despeito das distintas conjunturas internacionais que as influenciaram, nas duas primeiras fases do processo de fundação e consolidação da Geografia Política, que correspondem, conforme proposto por Vesentini (2010), aos períodos entre o final do século XIX até a Segunda Guerra Mundial e desta até a década de 1970, não se pode afirmar a existência de estudos relevantes nessa área, bem como na Geopolítica, que tenham consagrado qualquer agente que não fosse o Estado.

Não obstante, com o passar do tempo, cada área temática assumiu características próprias. A Geografia Política foi se configurando, cada vez mais, como um estudo acadêmico das relações entre política/poder e espaço, ainda que sob a égide de um pensamento baseado na atuação do Estado, ao passo que a Geopolítica se consolidou como um campo de análise voltado às formulações geoestratégicas estatais.

Assim, como fruto da sua afirmação como disciplina acadêmica, progressivamente destituída de um compromisso com uma análise de base estatal, e influenciada, como toda a ciência geográfica, pelas transformações decorrentes da renovação crítica, a partir da década de 1970 - que corresponde à terceira fase do processo de formação e consolidação da disciplina -, a Geografia Política passou por um "renascimento" (Idem, p. 134). Uma das consequências de tal processo, talvez a mais contundente, foi a ascensão de outros agentes como foco de análise da relação entre política/poder e espaço.

A partir de então, novos estudos e novas discussões são agregados ao conjunto de temas que interessam à Geografia Política e, ainda que com a figuração do Estado em muitos desses postulados, sem 
a centralidade outrora ocupada por esse agente. Nas palavras de José William Vesentini:

o Estado deixou de ser o ator político privilegiado (e praticamente exclusivo) e agora existe uma ênfase no(s) poder(es), que não se identifica somente com o Estado embora, evidentemente, também com ele -, mas com vários outros fenômenos ou sujeitos (...) (Ibidem, p. 134).

Além disso, ao longo dos últimos decênios, os estudos relativos ao território - conceito basilar para o temário da Geografia Política vem passando, também, por um processo de revigoramento, principalmente por conta do redimensionamento da abordagem territorial em meio aos novos paradigmas da globalização/fragmentação dos espaços habitados e à atuação crescente de novos agentes (e de outros, antigos, mas antes negligenciados) na conformação das relações entre política/poder e espaço.

Como observado por Saquet $(2011$, p. 15), as décadas finais do século XX formam um período de revisão e atualização do debate acerca da abordagem territorial, o que, por um lado, contribuiu para a identificação do território não mais como um mero "suporte da sociedade, sem homens ou configurado biologicamente por animais que 'controlam'-disputam certas áreas" e, por outra parte, "Há superação daquela ideia de território e poder centrada nas forças, ações e estratégias do Estado (...)".

O território, até então concebido apenas como a "extensão do espaço geográfico onde um Estado nacional exerce, com exclusividade, o domínio político-administrativo" (NASCIMENTO JúNIOR, 2011, p. 50), passa a ser considerado como um conceito cujos significados epistemológico e ontológico estão no fato de ser, ao mesmo tempo, uma instância espacial de poder, um produto social historicamente definido, relacional, multiescalar e multidimensional. Essas relações se configuram por meio de dominação e influência exercidas por agentes os mais diversos.

$\mathrm{Na}$ esteira de todas essas transformações, atualmente, a Geografia Política abrange, nos seus estudos, uma miríade de temas que abarcam a atuação de agentes os mais diversos, em diferentes perspectivas escalares (CASTRO, 2005). Contudo, não se pode deixar de considerar 
que a perda de centralidade do Estado nos estudos que tratam da relação entre política/poder e espaço - com o irrevogável caráter territorial que the é inerente (COSTA, 1992) -, significa, tão somente, um redimensionado do seu papel, mas nunca um esmaecimento.

Nesse sentido, é fundamental observar que, se em determinadas situações que mereçam um olhar mais atento dos estudiosos da Geografia Política, o Estado não aparece como agente principal das ações em exame, sua atuação pode ser percebida como a de um viabilizador ou, em sentido inverso, como aquele que dificulta/impede o desfecho de uma dada relação político-territorial. Assim, quando da atuação, por exemplo, de agentes econômicos, sujeitos em mobilização política e populações em movimento (os casos a serem abordados adiante), o papel do Estado pode não ser o mais ostensivo, mas, de alguma maneira, está presente, como se verá na terceira seção deste escrito.

\section{OESTE BAIANO: REESTRUTURAÇÃO PRODUTIVA E TRANSFORMAÇÕES TERRITORIAIS}

O termo Oeste Baiano (Figura 1) é designativo da parcela do território da Bahia que está disposta, em sua totalidade, na margem esquerda do Rio São Francisco, onde vivem cerca de 1,1 milhão de habitantes, distribuídos em 35 municípios. O emprego desse topônimo - e da regionalização que lhe cabe - visa, por um lado, diferenciar o fragmento territorial em análise daqueles que historicamente foram elaborados a partir dos ditames de órgãos oficiais (federais e estaduais) de planejamento e gestão do território, cujas formulações são insuficientes na captação de toda a complexidade social, econômica, política e cultural desta parte do Estado da Bahia. Por outro lado, tal configuração resgata a dimensão geográfico-histórica do termo "Além São Francisco", amplamente utilizado em outros tempos, mas que caiu em desuso por conter uma forte carga ideológica, conforme descrito alhures.

Ao longo das últimas quatro décadas, partes desse território têm passado por vigorosas transformações, resultantes, em grande medida, da formação de regiões produtivas agrícolas (ELIAS, 2012), principalmente nos cerrados baianos, com a produção de grãos nas 
parcelas mais ocidentais dos municípios de Barreiras, Correntina, Luís Eduardo Magalhães, Formosa do Rio Preto, Riachão das Neves e São Desidério, e no vale do Sub-Médio São Francisco, onde se desenvolve a vitivinicultura, que, no âmbito do que aqui se propõe como Oeste Baiano, abarca o Município de Casa Nova.

Alguns fatores tiveram papel preponderante na introdução da agricultura modernizada no Oeste Baiano, tais como: (a) solos de fácil manejo, a despeito da pouca fertilidade (no caso dos cerrados); (b) disponibilidade hídrica garantida pelo regime de chuvas e/ou pela grande quantidade de rios "solícitos" à irrigação (em se tratando da vitivinicultura, o Rio São Francisco é o único fornecedor de água); (c) relevo plano dos Gerais (facilitação ao uso de maquinário necessário ao plantio de soja e outros grãos); (d) condições climáticas favoráveis à plena maturação da uva para produção de vinhos; (e) baixos preços da terra rural e ( $f$ ) incentivos, por meio de pesquisas e créditos (ambos auspiciados pelo Estado brasileiro), à agricultura de larga escala.

Figura 1. Mapa da Bahia, com destaque para o Oeste Baiano

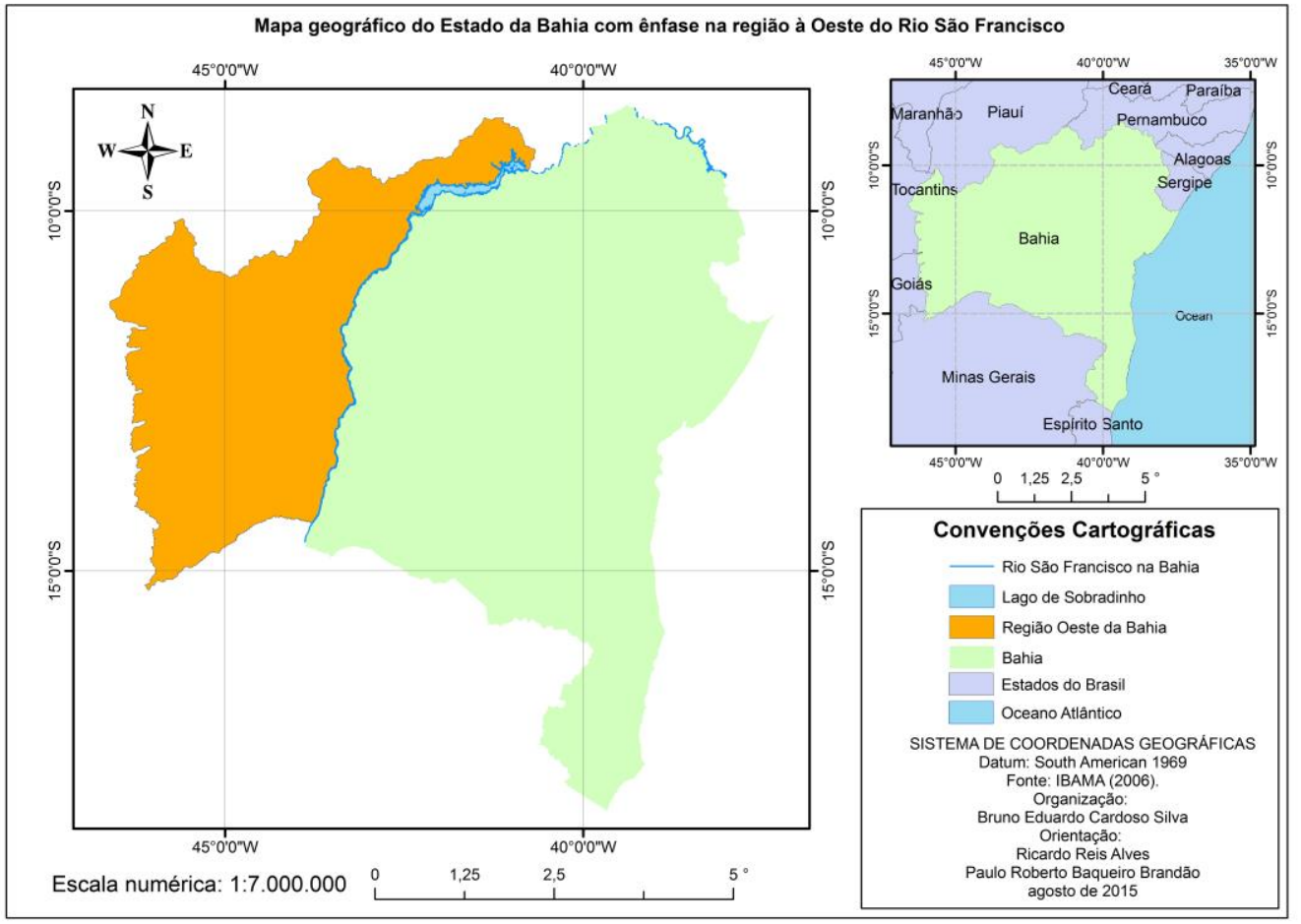

Fonte: elaboração própria (2015). 
Em conformidade com o que ocorrera em outras frentes de expansão agrícola no interior do Brasil, a implantação da agricultura de alto rendimento no Oeste Baiano foi acompanhada pela constituição de uma nova estrutura técnico-produtiva, posto que o território deva estar apto para a reprodução do capital.

Além disso, a migração induzida pelo Estado, para produtores oriundos, principalmente, do Sul do Brasil, e aquela motivada pela necessidade de força de trabalho, que gerou mobilidade de trabalhadores de outras partes da Bahia e do Nordeste, acabaram por fomentar, também, significativas transformações de caráter territorial.

Para além dos discursos de progresso e prosperidade propagados, em uníssono, pelo Estado e agentes econômicos, o resultado dos processos acima aventados é o desmantelamento das bases econômica, política, social e da estrutura fundiária precedentes - com severas implicações ambientais - e a instauração de outras, comandadas pelos desígnios de uma ordem global.

Assim, novos usos do território foram possíveis graças à implantação conjunta da psicosfera e tecnosfera (SANTOS, 2002) necessárias ao bom funcionamento dos negócios, à fluidez do capital e dos bens e à ascensão de novas elites, essas últimas sequiosas por conduzir, no Oeste Baiano, as transformações que permitam a reprodução, ad eternum, dos seus interesses corporativos.

\section{TRÊS QUESTÕES EMERGENTES: LIMITES, SECESSÕES E MIGRAÇÃO ESTRANGEIRA}

Emergem dos processos anteriormente aventados novas questões que tornam mais complexas as relações político-territoriais na vastidão ocidental da Bahia, como nos casos da conformação dos limites interestaduais, dos movimentos por criação de novos municípios e do próprio Estado do (Rio) São Francisco, além da mobilidade de pessoas oriundas de outros países, atraídas pela possibilidade de realização de negócios rentáveis.

\subsection{Os limites interestaduais}


Segundo Raffestin (1993), toda delimitação territorial traz embutida consigo uma questão de poder que é substantivada pela ação de um dado ator operando no território com o intuito de tornar viável o seu projeto. $O$ ilustre geógrafo suíço considera ainda que essas relações entre os ditos atores e as delimitações territoriais são marcadas por uma tensão, existente sempre que os limites interfiram na sua ação, ou, ao contrário, por uma ênfase na importância de tais limites, quando estes são considerados apropriados.

Além disso, Evangelista (1998) menciona que, segundo Yves Lacoste, no âmbito do Estado, há uma geopolítica externa, que lida com as tratativas políticas entre países, e uma geopolítica interna, que trata das relações estabelecidas entre as unidades supranacionais, o que envolve, entre outros temas, questões de limites.

Assim, é possível inferir, a partir do que fora exposto anteriormente, que os limites entre territórios são preservados quando asseguram a ocorrência de um projeto de poder, mas podem ter sua alteração requerida e, a depender da correlação de forças envolvidas, efetivada sempre que sejam considerados entraves às ações de um agente, tal raciocínio valendo tanto para delimitações entre países ou para aquelas em âmbito supranacional.

Quanto ao Oeste Baiano, no que se refere aos limites interestaduais, a querela é reestabelecida a partir de uma antiga questão: sua origem remonta às décadas iniciais do século $X X$, quando as técnicas empregadas na realização de levantamento topográfico, demarcação e mapeamento de áreas eram infinitamente inferiores se comparadas às atuais.

Segundo as partes reclamantes, isso permitiu que ocorressem graves erros na formação das linhas divisórias da porção mais ocidental da Bahia com Goiás, Piauí e Minas Gerais (cabe lembrar que o Tocantins só veio a existir com a promulgação da Constituição de 1988, por desmembramento da porção norte goiana). Segundo trabalho realizado na década de 1930 pelo Departamento Nacional de Estatística (predecessor do IBGE), com o intuito de estabelecer a sistematização provisória dos limites internos e externos do país, as linhas divisórias mais ocidentais da Bahia eram assim determinadas, iniciando pelo Estado do Piauí (BRASIL, 1933, p. 26): 
começando no divisor geral entre a bacia do rio S. Francisco e a do rio Parnaíba, no ponto da serra da Tabatinga em que começa um contraforte que faz parte do divisor de águas Parnaíba-Tocantins, acompanha para leste o divisor da bacia franciscana, além da citada serra de Tabatinga, as serras da Gurgueia, do Piauí e dos Dois Irmãos, alcançando nesta o ponto que defronta a serra das Marrecas.

Quanto aos limites com o Estado de Minas Gerais, evidenciando apenas a parte que divisa aquela unidade federativa das terras que compõem o Oeste Baiano, a descrição afirma que "(...) desce o rio S. Francisco até á barra do rio Carinhanha, e sóbe por êste ás suas nascentes e daí ao alto da serra Paranã" (BRASIL, 1933, p. 27).

Por fim, estabelece-se os limites com Goiás, constando também as divisas com o atual Estado do Tocantins, que, então, era parte do anterior:

começando no alto da serra Paranã, no ponto fronteiro á cabeceira do rio Carinhanha, segue para o norte acompanhando o divisor geral da bacia do Rio S. Francisco, passando pelas serras de Santa Maria, S. Domingos, Taguatinga e Duro, e atravessa, em seguida, o chapadão das Mangabeiras, onde passa, por uma reta, pelo meio da lagôa do Veredão, onde se originam os rios Soninho e Sapão, êste da bacia do S. Francisco, e aquele da bacia do Tocantins, para ir terminar na serra de Tabatinga, no ponto em que dela se destaca a ramificação que faz parte do divisor de águas Parnaíba-Tocantins (BRASIL, 1933, p. 28).

As informações contidas nas descrições evidenciam o pouco apuro na demarcação das divisas, o que suscitou os problemas que estão em pauta. Por outro lado, a datação do estudo revela a antiguidade das divisas, as mesmas que, durante todo esse período, não foram objeto de contestações das partes ora em litígio.

Rincões perdidos na vastidão dos cerrados baianos, abrigo de populações tradicionais, as distantes terras que compõem os limites interestaduais passaram décadas a fio sob o ritmo lento da vida que transcorria na mediação direta entre homem e natureza, sem gerar interesse nos governantes e agentes econômicos de ambos os lados das unidades federativas que se justapõem. Atualmente, porém, essas zonas limítrofes são consideradas verdadeiras "galinhas dos ovos de ouro" por 
sua aptidão à agricultura de alto rendimento, fato que vem pautando as reivindicações das partes em litígio.

Recentemente, os representantes legais dos estados da Bahia e Tocantins chegaram a um acordo sobre o dito litígio territorial: as partes entraram em consenso sobre os limites, que serão considerados segundo as cartas elaboradas pelo Instituto Brasileiro de Geografia e Estatísticas - IBGE, sem perdas significativas para nenhum dos lados.

$\mathrm{Na}$ resolução do imbróglio que envolveu o Tocantins, o Governo da Bahia delegou à Associação dos Agricultores e Irrigantes da Bahia Aiba $^{3}$, sediada em Barreiras, o papel de formuladora das argumentações jurídicas, bem como da relatoria da defesa dos interesses baianos. Tal ação permite dimensionar o nível de integração e a forte convergência de interesses entre o Estado e o capital.

Por outro lado, em matéria veiculada em fevereiro de 2012, o Jornal Estado, de Anápolis (Goiás), repercute reunião no Superior Tribunal de Federal, cuja pauta era justamente a demarcação das divisas entre os estados de Goiás e Bahia. Segundo a referida matéria:

\begin{abstract}
o vice-governador José Eliton saiu da audiência do STF dizendo que foi um encontro muito importante para defender o interesse de Goiás na questão territorial com a Bahia. "Goiás ganhará uma área significativa numa região considerada grande produtora de grãos". Além disso, José Eliton lembra que haverá um incremento de arrecadação de impostos e pacificação entre os produtores rurais que ora recebem títulos de suas terras pelo governo da Bahia e ora pelos órgãos similares de Goiás (JORNAL ESTADO, 2012, p. 4).
\end{abstract}

Com um discurso em outra direção, o geógrafo Teixeira Neto (2004, p. 17), proeminente estudioso da formação territorial de Goiás, assevera que as questões que opuseram aquele estado e a Bahia no início do século XX "não passaram de bravata política". Ademais, ao analisar o caso da Bahia no conjunto das contendas territoriais goianas com outras federações limítrofes, o autor faz menção apenas ao litígio referente ao Jalapão (atualmente pertencente ao Estado do Tocantins).

Aliás, por considerar que a questão goiano-baiana já tivera resultado satisfatório no acordo firmado no início do século XX, Teixeira

3 A dita associação representa os grandes latifundiários e empresas agrícolas e agroindustriais atuam no Oeste Baiano.

Redes (St. Cruz Sul, Online), v. 20, n 3 - Suplemento, p. 382 - 400, set./dez. 2015392 
Neto sequer mencionou os fatos que hoje opõem os dois estados vizinhos. Para o autor, a questão em tela se resolveu quando, em 9 de setembro de 1919, os governantes de Goiás e da Bahia assinaram um acordo bilateral "instituindo que as fronteiras e limites entre os dois estados passariam pelo divortio aquarium (divisor de águas) da Serra Geral de Goiás" [itálico no original]. (TEIXEIRA NETO, 2004, p. 45).

Como se pode inferir pelo exposto acima, o desfecho do problema entre Bahia e Tocantins não significa, porém, que a questão esteja resolvida no seu todo. Há pendências a serem acertadas entre a Bahia e os estados de Goiás, Piauí e Minas Gerais, fato que gera apreensão nos produtores rurais alocados no extremo ocidente baiano e expectativas nos governantes.

\subsection{As secessões}

No Brasil, os debates sobre secessão - nos âmbitos estadual e municipal - envolvem, em última instância, a compreensão do modelo de federalismo adotado, este pautado, por sua vez, no que está posto nos Artigos $1^{\circ}$ e 18 da Constituição Federal, promulgada em 1988, naquilo que concerne aos entes federados. Ambos os trechos tratam da formação da República Federativa do Brasil e de sua organização político-administrativa, compreendendo a União, os Estados (e o Distrito Federal) e os Municípios como entes federados, todos detentores de autonomia (BRASIL, 2013; TOMIO, 2005).

Quanto ao federalismo, Anderson (2009) afirma ser este um sistema que, a despeito da grande variação de características encontradas de um país para outro, possui como elementos comuns: (a) um mínimo de dois níveis de governo, (b) uma constituição escrita e que atribui competências a cada um desses distintos níveis de governo, (c) garantia de representação das unidades federadas junto ao Poder Legislativo, (d) procedimentos para decidir disputas entre os níveis de governo e (e) um conjunto de processos e instituições que conduzem as relações intergovernamentais.

Há aí, portanto, uma repartição de poderes que garante autonomia àquelas unidades que constituem a federação. Sobre isto, Anderson (2009, p. 21) afirma que "nos sistemas federativos, cada esfera de governo tem sua própria existência constitucional autônoma”. 
Ademais, no que se refere aos entes que formam a federação, o mesmo autor pondera:

As federações geralmente se compõem de uma categoria principal de unidades constitutivas em nível subnacional, geralmente chamadas de estados ou províncias. Frequentemente, há também categorias secundárias (...). Em algumas federações, os municípios também são tidos como um terceiro nível de unidades constitutivas (ANDERSON, 2009, p. 35).

O Brasil é um dos raros exemplos de federação que se constitui de três níveis de governo, ou seja, União, Estados e Municípios, conforme preconiza a atual Constituição Federal, considerada a primeira que efetivamente concedeu a este último a condição de ente federativo, detentor de autonomia plena (SANTIN e FLORES, 2006).

Assim, graças aos poderes e autonomia garantidos pela Carta Magna brasileira, vêm se tornando cada vez mais comuns as tentativas de fragmentação territorial, tanto com vistas à criação de novos estados quanto de municípios. Tal situação é especialmente observável nas já mencionadas regiões produtivas do agronegócio.

Segundo Martins (2001, p. 280), ao analisar os processos de criação de novos estados, os pleitos separatistas "são resultantes do processo de modernização agrícola de conexões globais, vinculado, principalmente, ao complexo agro-industrial da soja (...)". Isso, aliado à afirmação de Haesbaert (1996, p. 390), para quem "estes novos estados legitimariam, num sentido político-territorial, a área dominada pelas redes da moderna agricultura capitalista", evidenciam que, nessas regiões, as elites que surgiram com a formação de importantes cinturões agrícolas buscam ampliar as condições para a reprodução do capital através do agronegócio.

No âmbito municipal, a lógica se repete: Silva (2009, p. 88-89) chama a atenção para aquilo que denomina de família de municípios do agronegócio, que seria

(...) um conjunto de municípios novos ou municípios antigos com novas infra-estruturas, que surgem como resposta às solicitações do mercado para uma produção moderna, tendo em comum uma única dinâmica econômica a lhes imprimir seu movimento. São municípios que se inserem como órgãos "derivados" no 
organismo regional, reorganizando a antiga ordem do conjunto para impor novos usos regionais não mais somente a partir de uma ordem local, mas, sobretudo, a partir de uma ordem global.

A existência (real ou pretensa) desses municípios está visceralmente atrelada à formação de um pensamento hegemônico por parte das elites regionais que urgem pela consolidação de uma base garantidora da implantação das condições técnicas, normativas e organizacionais que ampliam as possibilidades de reprodução do capital através do agronegócio.

No caso do reivindicado Estado do (Rio) São Francisco, é possível identificar a existência de alguns mitos fundadores, entre os quais vale destacar aqueles que evocam principalmente aspectos referentes (a) à negligência do poder estatal baiano nos assuntos políticos e econômicos da região; (b) ao desequilíbrio entre as riquezas produzidas regionalmente e a sua devida apropriação; (c) ao remoto passado regional, que descolaria a antiga Comarca de São Francisco da Província da Bahia, e, enfim; (d) à inexistência de uma identidade baiana "pura" entre os habitantes do Oeste.

A gestação desses argumentos se dá, segundo Haesbaert (1996, p. 397), a partir da evocação de "raízes históricas" (distância temporal que separa o Oeste Baiano de Pernambuco) e "raízes geográficas" (distância física de Salvador, o centro de gestão do território e de difusão da baianidade). De forma ambígua, o distanciamento geográfico-histórico é encarado negativamente, quando serve de argumento para sustentar que o "Além São Francisco" não deve estar ligado a Pernambuco ou à Bahia, mas de forma positiva, quando é tomado como o elemento principal de construção da identidade territorial oestina, que não se vincula àquela que, para efeito de mídia, é dominante, ou seja, a dita baianidade.

No que se refere à criação de novos municípios no Oeste Baiano (Figura 2), as pretensões partem principalmente de localidades como Roda Velha (São Desidério), Rosário (Correntina) e Vila Coaceral (Formosa do Rio Preto), cuja estratégia reivindicatória é a mesma que resultou na emancipação de Luís Eduardo Magalhães, há mais de uma década, ou seja, pela consolidação de três processos concomitantes e complementares: o crescimento da agricultura moderna nos cerrados 
oestinos, o aumento da população nas nucleações urbanas mais próximas às áreas ocupadas para a produção de grãos e a pressão política das elites que se formaram em tais localidades.

Figura 2. Localidades do Oeste Baiano que reivindicam emancipação municipal

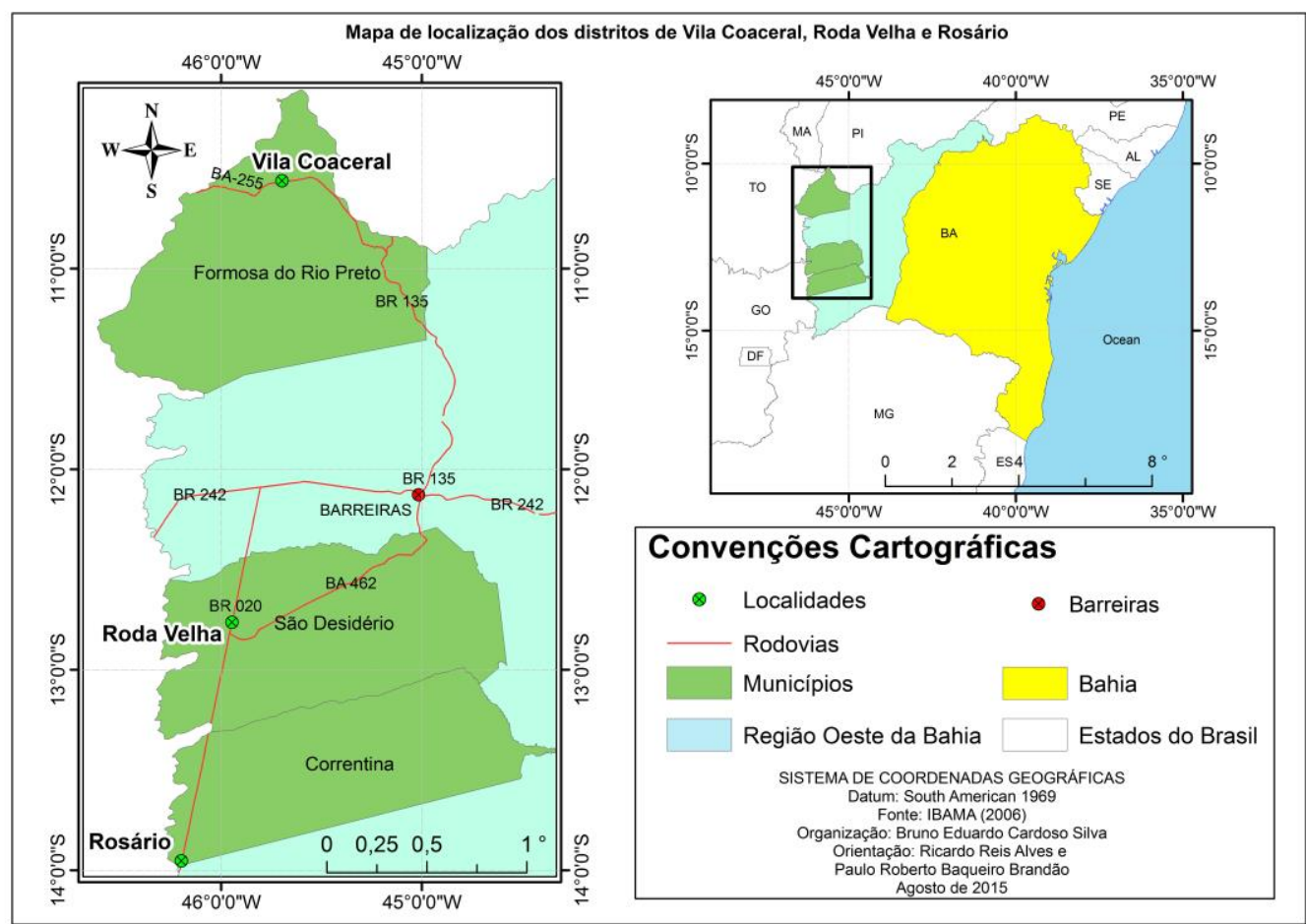

Fonte: elaboração própria (2015).

Os argumentos para a separação dos municípios aos quais ora estão vinculados são os mesmos empregados pelos grupos que defendem a criação do Estado do (Rio) São Francisco: a pretensa existência de distanciamentos histórico e geográfico em relação aos centros de gestão do território (HAESBART, 1996). No primeiro caso, a alegação é de que a fundação de nucleações nos Gerais não se vincula ao processo de formação dos territórios municipais, tendo sido mais recentes e ligadas à migração sulista e à agricultura modernizada. No que diz respeito à argumentação de foro geográfico, os grupos separatistas afirmam que a distância em relação às sedes municipais tornam as gestões públicas municipais pouco "presentes" nas localidades.

Desde o ponto de vista dos grupos políticos locais, vale mencionar que, de forma contraditória, prefeitos de municípios que 
seriam retalhados para a criação de novas unidades políticoadministrativas, confessos defensores da fundação do Estado do (Rio) São Francisco, engrossam as fileiras daqueles que reivindicam a manutenção dos territórios municipais em seus formatos atuais.

A criação de novos municípios implica em uma divisão que, além da óbvia subtração territorial, gera significativas perdas econômicas para a unidade político-administrativa cedente. Isso seria ainda mais evidente nos casos aqui mencionados, posto que as áreas reivindicadas estejam localizadas, via de regra, nos Gerais, onde a produção agroexportadora de grãos está concentrada. Deriva daí, portanto, o já mencionado posicionamento contraditório defendido por alguns dirigentes políticos locais.

Ademais, atualmente, o debate pela criação do Estado do (Rio) São Francisco e, em igual medida, aqueles voltados à promoção de emancipações municipais no Oeste Baiano têm sofrido com uma espécie de "refluxo". Em outras palavras, vive-se um momento pouco vibrante quanto às propostas, discussões e manifestações por desmembramentos. Isso decorre de alguns fatores, entre os quais, vale destacar:

- Na escala regional/estadual, o plebiscito que tratou da criação dos estados de Carajás e Tapajós, cujos territórios seriam cedidos pelo Pará, formalizou um resultado adverso desde o ponto de vista dos separatistas, tendo gerado, portanto, uma retração nas ações dos demais grupos favoráveis à implantação de novas unidades federativas existentes em todo Brasil.

- No âmbito municipal, o momento se mostra pouco favorável à criação de novas unidades, tanto do ponto de vista político quanto jurídico: a Presidenta Dilma Roussef vetou integralmente o Projeto de Lei 98/2002, de autoria do Senador Mozarildo Cavalcanti, que estipulava regras para criação, incorporação, fusão e desmembramento de municípios (GUERREIRO, 2013; PATU e GUERREIRO, 2013).

- Em ambas as escalas, claro está que não existem forças que tenham uma genuína capacidade aglutinadora ou mesmo um conjunto de propostas factíveis que provoquem um maior apelo popular para as causas separatistas. Por enquanto, os debates se 
encerram em pequenos círculos formados pelas elites locais e regionais.

Diante do exposto, fica evidente o quão carente em base técnica, estudos realistas e isenção e imparcialidade é o debate sobre a criação do Estado do (Rio) São Francisco e de novos municípios na região. Só a partir da adoção de um olhar sensato, será possível vislumbrar a real necessidade de se criar ou não um estado para o Oeste Baiano.

\subsection{A migração estrangeira}

Outro tema relevante, apesar de pouco aparente e ainda subdimensionado pela sociedade oestina, justamente por causa da sua atualidade, diz respeito à presença crescente de estrangeiros vivendo de forma dispersa no Oeste Baiano. Neozelandeses em Jaborandi, coreanos e norte-americanos em Formosa do Rio Preto, migrantes diversos em Luís Eduardo Magalhães e Barreiras, além da recente chegada de chineses e russos em Barreiras (atraídos pela soja e tálio, respectivamente), representam novos contingentes populacionais cujas profundas diferenças culturais deixam (ou podem vir a deixar) marcas na sociedade regional.

O fenômeno da migração sempre foi um elemento importante como contributo ao incremento populacional do Oeste Baiano. No entanto, só recentemente os migrantes de outros países se tornaram um contingente numericamente perceptível. Há pouco tempo, a presença estrangeira no Oeste Baiano se restringia aos capitais investidos principalmente em propriedades rurais e empreendimentos industriais e a poucos indivíduos que, de modo espontâneo, escolheram as terras mais ocidentais da Bahia para viver. Nos dias atuais, porém, já é possível perceber uma mudança nesse panorama, com a fixação crescente de pequenos e médios investidores estrangeiros, além de trabalhadores (em ambos os casos, com as famílias), gerando repercussões demográficas, sociais, econômicas e, provavelmente, políticas, estas últimas perceptíveis - certamente - em um futuro próximo.

Segundo Sassen (1988), atualmente, a mobilidade populacional entre países segue a mesma direção dos fluxos internacionais de capital. Assim, aqueles espaços que, de uma forma ou de outra, 
participam do mercado globalizado, tornam-se atrativos também para a fixação de novos habitantes originários de terras estrangeiras. Oliveira e Oliveira (2011) corroboram com tal afirmação ao observarem que, no Brasil, a migração estrangeira se dá pela formação de novos espaços de atração de população, para os quais se estabelecem fluxos em consonância com as atuais mudanças econômicas e sociais.

Contudo, vale salientar, diferente dos fluxos migratórios estabelecidos em outros períodos da história nacional, atualmente, a mobilidade geradora de incremento populacional é fragmentada quanto aos contingentes e origens e multifacetada quanto às motivações, tornando-se um fenômeno extremamente complexo (NACIONES UNIDAS, 2006).

Para Oliveira (2011), tais mudanças são parte das transformações de caráter social, político e econômico mais amplas, geradas no âmbito da instauração do pós-fordismo - em convivência com os modos de produção que o precedem - e dos consequentes processos de flexibilização e precarização do trabalho. Ao interpretar o pensamento de George Benko sobre o tema, Oliveira afirma:

ainda na linha da relação capital-trabalho no novo padrão de acumulação, o surgimento dos métodos de produção enxuta seguiria de mãos dadas com as práticas empresariais reinantes de subcontratação, terceirização, estabelecimento de negócios no exterior, consultoria, redução do quadro funcional e produção sob encomenda. A mobilidade da força de trabalho diria respeito tanto a trabalhadores não qualificados quanto a qualificados. (Oliveira, 2011, p.22)

E segue:

Pode-se levar em consideração a bipolaridade da força de trabalho na atual etapa do desenvolvimento econômico, que demanda trabalhadores altamente especializados e semiqualificados e a estratégia do capital, global e regional, de buscar espaços onde a mão de obra fosse mais barata e não houvesse restrições ambientais. Neste caso, poder-se-ia inferir que, se adicionarmos a inserção ocupacional da mão de obra e a articulação entre espaços às dimensões de poder, inovação tecnológica, território e relações de trabalho, esse conjunto de fatores estaria diretamente associado às formas como se comportam as migrações na contemporaneidade, sejam as de caráter interno ou internacional (Oliveira, 2011, p. 22-23). 
Nesse aspecto, o caso do Oeste Baiano converge com o exposto anteriormente, ao menos no que diz respeito ao estabelecimento de negócios e fixação de mão de obra especializada e semiqualificada, posto que, nos últimos anos, a migração estrangeira resulte, na grande maioria das vezes, tanto da implantação de novos empreendimentos agrícolas e agroindustriais, quanto da atração de trabalhadores para execução de atividades especializadas e de liderança nessas empresas. No entanto, há também os casos mais específicos de formação de colônias agrícolas, como se verá em alguns dos exemplos examinados a seguir.

Em Jaborandi, município com extensão de $9.545 \mathrm{~km}^{2}$ e população de 8.973 habitantes, localizado na porção mais meridional do Oeste Baiano, está em operação a Fazenda Leitíssimo, "espécie de comunidade que um grupo de neozelandeses fundou há dez anos" (KUCHLER, 2012, p. 45) e cuja produção de leite é baseada em técnicas igualmente vindas da Nova Zelândia.

Na propriedade, além dos sistemas de engenharias que garantem o pleno funcionamento das atividades relativas à produção leiteira, há toda uma estrutura para as famílias dos migrantes e dos empregados, contando, inclusive, com uma escola bilíngue, que mantém em seus quadros professoras de origem brasileira e neozelandesa.

Ainda segundo Kuchler (p. 46), está em plena vigência um processo de interpenetração entre culturas que se dá no âmbito das técnicas de produção, na formação educacional de crianças, jovens e adultos e, inclusive, nas relações matrimoniais. Um exemplo emblemático é dado pela autora, que, em visita à escola, presenciou crianças ensaiando uma música composta pelo próprio grupo que versava sobre "two pães de queijo, five goiabadas, six veadinhos".

Quanto aos sul-coreanos e norte-americanos, ambos os grupos compõem um fenômeno marcado, até o presente momento, pela autossegregação e, portanto, pouco compreendido, mesmo em Formosa do Rio Preto, município onde ocorre.

O Município de Formosa do Rio Preto, cuja área é de 16.304 km², onde vivem 22.528 habitantes, e localizado no noroeste do estado, abriga pequenas colônias agrícolas fundadas por sul-coreanos e norteamericanos. No primeiro caso, pouco se sabe sobre as origens, 
motivações para a migração ou atividades que realizam. Em entrevista realizada em 03 de julho de 2014, um funcionário da Prefeitura Municipal de Formosa do Rio Preto afirmou que a presença sul-coreana teve início há cerca de quatro anos, com as primeiras aquisições de terra. Os migrantes asiáticos seriam, ainda segundo o entrevistado, um grupo reservado.

Quanto aos norte-americanos, segundo Arruda (2007, p. 4A), tal migração ocorre em várias partes do Brasil e os grupos são formados por pessoas físicas ou a partir de interesses corporativos de empresas e fundos de pensões, que "apostam no futuro de commodities agrícolas, como soja, algodão e celulose". Ainda segundo o jornalista:

\begin{abstract}
chama atenção o que ocorre agora no oeste da Bahia - região de cerrado, na fronteira com o Tocantins, ao pé da Serra Geral de Goiás e a 900 quilômetros de Salvador. Fazendeiros americanos, com dificuldades para comprar terras em seu país, começaram a desembarcar por ali em meados dos anos 90, para produzir milho e algodão - e não pararam mais.
\end{abstract}

No Município de Formosa do Rio Preto, um dos grupos de migrantes norte-americanos fundou o condomínio agrícola chamado Associação American Colony, em área de 18 mil hectares e sede na cidade. Em Luís Eduardo Magalhães, conforme verificado por R. Arruda, em 2007, cerca de 60 propriedades pertenciam a estrangeiros, totalizando $150 \mathrm{mil}$ hectares em terras.

De acordo com Sauer e Leite (2012), esse processo de estrangeirização da propriedade fundiária no Brasil teve um considerável incremento nos últimos anos, seja para plantio direto, com ênfase na produção direta e beneficiamento de commodities agrícolas (soja e cana-de-açúcar como principais escolhas), na exploração florestal, mas também na mineração, como se poderá observar nos exemplos que seguem.

No ano de 2008, em São Desidério, entrou em operação aquela que é considerada a maior esmagadora de caroço de algodão da América Latina, de propriedade da Agrícola Xingú S/A, um consórcio empresarial formado pela junção de capitais norte-americano, chinês e brasileiro. Em 2011, foi lançada, em uma das margens da BR 242, em área do Município de Barreiras próxima à cidade de Luís Eduardo 
Magalhães, a pedra fundamental da esmagadora de soja da Chongqing Dragonfly Oil, empreendimento de capital chinês.

Também em 2011, a empresa Itaoeste Serviços e Participações LTDA anunciou a descoberta de uma jazida de tálio próximo à localidade de Val da Boa Esperança, no Município de Barreiras. O dito mineral é considerado extremamente raro, de alto valor no mercado desse tipo de commodities e cuja aplicação é feita na medicina, engenharia elétrica e na produção de componentes de informática. Segundo Aps (s/d), quando o processo de extração do mineral estiver em operação, a área total do projeto terá uma extensão de 44.000 ha, dos quais 770 ha serão destinadas à lavra.

De acordo com informações de representantes da Companhia Baiana de Pesquisa Mineral, uma empresa de capital russo, em associação com a Itaoeste, iniciou análises prospectivas visando avaliar o potencial de extração do minério.

Assim, tanto no caso das iniciativas agroindustriais, quanto da mineração, dirigentes empresariais e trabalhadores especializados saídos, respectivamente, dos EUA, China e Rússia estão fixados no Oeste Baiano, principalmente em Barreiras e Luís Eduardo Magalhães.

Como parte do anteriormente exposto, é possível considerar que tomam forma, no Oeste Baiano, novos arranjos políticos territoriais que, a exemplo do que ocorrerá nas décadas finais do século XX, colocam em evidência o papel do imigrante como agente, ainda que, no caso hodierno, populações estrangeiras são as protagonistas.

Com o passar do tempo e a progressiva assimilação mútua da população oestina e dos grupos estrangeiros, novas formas de articulação social, econômica e política podem ser geradas, o que certamente ocorrerá sob condições ora harmônicas, ora conflituosas. Além disso, esses novos grupos (e os que resultarão de um inevitável processo de miscigenação) passarão a reivindicar maior participação nos temas locais e regionais, algo absolutamente legítimo, o que, ao fim e ao cabo, resultará na formação de novos arranjos políticos (não necessariamente partidários), como já ocorre em todos esses anos de presença sulista no Oeste Baiano. 


\section{CONSIDERAÇÕES FINAIS}

As questões brevemente abordadas nestas linhas permitem inferir que a conformação da geografia política do Oeste Baiano resulta das permanências e transformações que, ao longo do tempo, deram forma ao território. Importante destacar, ademais, que os aspectos que colocam em evidência a relação entre política/poder e espaço tem sua raiz na economia.

Se as querelas que ora opõem a Bahia e os estados que lhe são fronteiriços em sua banda ocidental foram reacendidas a partir da implantação, nos cerrados baianos, da agricultura de alto rendimento, de igual modo, as questões atinentes às secessões municipais, à pretensa criação do Estado do (Rio) São Francisco e à mobilidade populacional que tem fixado estrangeiros em número crescente na região também se originam de motivações estritamente econômicas. Assim, seja pelo interesse em promover a redistribuição das riquezas oriundas do agronegócio em escalas municipal e estadual, seja pelo movimento de pessoas em busca de novas oportunidades de reprodução do capital, o fato é que essa nova geografia política se substantiva por meio de uma também nova geografia econômica regional.

Vale mencionar, ainda, que outros temas por certo mereceriam engrossar o debate, tais como a questão da apropriação e uso das águas superficiais e subterrâneas, as contradições do modelo fundiário vigente, as relações entre Estado e elites econômicas, entre tantos que acabaram escapando do panorama aqui esboçado e que fazem das terras oestinas uma das parcelas mais dinâmicas, complexas e pouco compreendidas do Estado da Bahia.

\section{REFERÊNCIAS}

ANDERSON, George. Federalismo: uma introdução. Rio de Janeiro: FGV, 2009.

APS, Vladimir. O depósito de tálio de Barreiras, Bahia: significado e perspectivas. São Paulo: Itaoeste Serviços e Participações LTDA., s/d (notas de apresentação). 
ARRUDA, Roldão. Incra acende sinal de alerta contra compra de terras por estrangeiros. Jornal O Estado de S. Paulo, Seção de Política, p. 4, Edição de 8 mai. 2007.

BRANDÃO, Paulo Roberto Baqueiro. Um território indiferenciado dos sertões: a geografia pretérita do Oeste Baiano (1501-1827). Boletim Goiano de Geografia, Goiânia, v. 29, n. 1, p. 47-56, 2009.

A formação territorial do Oeste Baiano: a constituição do "Além São Francisco" (1827-1985). GeoTextos, Salvador, v. 6, n. 1, p. 35-50, 2010.

BRASIL. Estados Unidos do. Limites dos Estados Unidos do Brasil. Sistematização provisória das linhas de limites do território da República e do de cada uma das suas unidades políticas. Rio de Janeiro: Departamento Nacional de Estatística, 1933.

BRASIL, República Federativa do. Constituição da República Federativa do Brasil. Texto promulgado em 05 de outubro de 1988. Brasília: Senado Federal, 2013.

CASTRO, Iná Elias de. Geografia e Política. Território, escalas de ação e instituições. Rio de Janeiro: Bertrand Brasil, 2005.

COSTA, Wanderley Messias da. Geografia Política e Geopolítica. Discursos sobre o território e o poder. São Paulo: Hucitec, 1992.

ELIAS, Denise. Relações campo-cidade, reestruturação urbana e regional no Brasil. In: XII COLOQUIO INTERNACIONAL DE GEOCRÍTICA, Bogotá, 7 a 11 de maio de 2012, Anales... Bogotá: Universidad Nacional de Colombia, 2012, p. 1-16.

EVANGELISTA, Hélio de Araújo. A fusão dos estados da Guanabara e do Rio de Janeiro segundo uma perspectiva de análise geográfica. 1998. 298 f. Tese de doutoramento do Programa de Pós-graduação em Geografia. Rio de Janeiro: Universidade Federal do Rio de Janeiro, 10 de março de 1998. 
Geografia Política/Ceopolítica Clássica a partir de uma dinâmica em sala de aula. Revista GeoNorte, Manaus, Edição Especial 3, v. 7, n. 1, p. 115-130, 2013.

GUERREIRO, Gabriela. Senado abre brecha para criação de 180 cidades. Jornal Folha de S. Paulo, São Paulo, Seção Poder, p. A10, Edição de $17 / 10 / 2013$.

HAESBAERT, Rogério. "Gaúchos" e baianos no "novo" Nordeste: entre a globalização econômica e a reinvenção das identidades territoriais. In: CASTRO, Iná E.; GOMES, Paulo César da C.; CORRÊA, Roberto L. (org.). Brasil. Questões atuais da reorganização do território. Rio de Janeiro: Bertrand Brasil, 1996, p. 367-415.

La Blache, Ratzel e a "Geografia Política". GEOgraphia, Niterói, v. 4, n. 7, p. 81-83, 2002.

KUCHLER, Adriana. Milk quente. Revista Serafina. Suplemento do Jornal Folha de S. Paulo, São Paulo, p. 44-47, 26 dez. 2012.

Litígio territorial próximo do final. Jornal Estado, Anápolis, p. 4, 25 a 28 fev. 2012.

MARTINS, Herbert Toledo. A fragmentação do território brasileiro: a criação de novos estados no Brasil. Caderno $C R H$, Salvador, n. 35, p. 263-288, 2001.

NACIONES UNIDAS. Asamblea General. Resumen del diálogo de alto nível sobre la migración internacional y el desarrollo. Nueva York: Naciones Unidas, 2006.

NASCIMENTO JÚNIOR, Francisco das Chagas do. Do uso corporativo ao uso subversivo do território nos países periféricos. Mercator, Fortaleza, v. 10 , n. 23 , p. $49-58,2011$.

OLIVEIRA, Luiz Antonio Pinto de e OLIVEIRA, Antônio Tadeu Ribeiro de. Introdução. In: OLIVEIRA, Luiz Antonio Pinto de e OLIVEIRA, Antônio 
Tadeu Ribeiro de (org.). Reflexões sobre os deslocamentos populacionais no Brasil. Rio de Janeiro: Instituto Brasileiro de Geografia e Estatística, 2011 , p. 8-9.

OLIVEIRA, Antônio Tadeu Ribeiro de. Algumas abordagens teóricas a respeito do fenômeno migratório. In: OLIVEIRA, Luiz Antonio Pinto de e OLIVEIRA, Antônio Tadeu Ribeiro de (org.). Reflexões sobre os deslocamentos populacionais no Brasil. Rio de Janeiro: Instituto Brasileiro de Geografia e Estatística, 2011, p. 10-26.

PATU, Gustavo e GUERREIRO, Gabriela. Dilma veta lei que permitia criação de até 269 municípios. Jornal Folha de S. Paulo, São Paulo, Seção Poder, p. A1 1, Edição de 15 nov. 2013.

RAFFESTIN, Claude. Por uma Geografia do Poder. São Paulo: Ática, 1993.

SANTIN, Janaína Rigo e FLORES, Deborah Hartmann. A evolução histórica do município no federalismo brasileiro, o poder local e o Estatuto da Cidade. Justiça do Direito, Passo Fundo, v. 20, n. 1, p. 56-69, 2006.

SANTOS, Milton. A natureza do espaço. São Paulo: Editora da Universidade de São Paulo, 2002.

SAQUET, Marcos. Por uma Geografia das territorialidades e das temporalidades: uma concepção multidimensional voltada para a cooperação e para o desenvolvimento territorial. São Paulo: Outras Expressões, 2011.

SASSEN, Saskia. The mobility of labor and capital. Cambridge: University Press, 1988.

SAUER, Sérgio e LEITE, Sérgio Pereira. Expansão agrícola, preços e apropriação de terra por estrangeiros no Brasil. Revista de Economia e Sociologia Rural, Piracicaba, v. 50, n. 3, p. 503-524, 2012. 
SILVA, Silvana Cristina da. A criação de municípios no front e a formação da elite do agronegócio: faces do uso do território brasileiro. Geosul, Florianópolis, v. 24, n. 48. p. 85-101, 2009.

TEIXEIRA NETO, Antônio. Evolução histórica e geográfica das fronteiras do estado de Goiás. In: TEIXEIRA NETO e outros (org.). O espaço goiano: abordagens geográficas. Goiânia: Associação dos Geógrafos Brasileiros, 2004, p. 9-57.

TOMIO, Fabrício Ricardo de Limas. Federalismo, municípios e decisões legislativas: a criação de municípios no Rio Grande do Sul. Revista de Sociologia e Política, Porto Alegre, n. 24, p. 123-148, 2005.

VESENTINI, José William. Repensando a Geografia Política. Um breve histórico crítico e a revisão de uma polêmica atual. Revista do Departamento de Geografia, São Paulo, n. 20, p. 127-142, 2010.

Submetido em $01 / 08 / 2014$

Aprovado em 16/11/2015

\section{Sobre os autores}

\section{Paulo Roberto Baqueiro Brandão}

Professor dos cursos de Geografia, Bacharelado Interdisciplinar em Humanidades e do Programa de Pós-graduação em Ciências Ambientais da Universidade Federal do Oeste da Bahia (UFOB), Campus Edgard Santos, em Barreiras (BA).

Endereço: Rua Professor José Seabra de Lemos, 316, Recanto dos Pássaros. 47808021

- Barreiras - BA - Brasil.

E-mail: paulobaq@ufba.br 